\title{
Cellulose Monoacetate/Nafion (CMA/N) Hybrid Nanofibers as Interface for Electrochemical DNA Biosensors
}

\author{
Ayse Bostanci ${ }^{1}$, Nilay Aladag Tanik ${ }^{1}$, Yakup Aykut ${ }^{2}$ \\ ${ }^{1}$ Textile Engineering, Graduate School of Natural and Applied Sciences, Uludag University, Bursa, Turkey \\ ${ }^{2}$ Textile Engineering Department, Engineering Faculty, Uludag University, Bursa, Turkey
}

Corresponding Author: Yakup Aykut, aykut@uludag.edu.tr

\begin{abstract}
Cellulose monoacetate/Nafion (CMA/N) hybrid nanofibers were produced via a one-step electrospinning method. Nanofibers morphologies transformed from uniform to bead on a string defect morphology with increasing Nafion ratio in CMA/N hybrid nanofibers. The melting point of CMA was detectable at DSC measurement, but since the addition of Nafion did not allow a proper crystallization of CMA, melting peak disappeared after the Nafion addition. Decomposition temperature decreased dramatically with the addition of Nafion into CMA/N nanofibers and decomposition took place at a broad temperature range. Nanofibers were also electrospun on the cylindrical graphite electrode for DNA electrochemical sensor analysis. Unmodified and NHmodified single strand DNA molecules were immobilized via physical adsorption method on the asprepared nanofiber sensory system. Electrochemical analysis were performed via differential pulse voltammetry (DPV) to observe the guanine oxidation signal at unmodified and NH-modified DNA. Maximum oxidation signals were detected from pure CMA nanofibers at unmodified DNA. Signal intensity increased with the addition of Nafion into CMA/N nanofibers at NH-modified DNA sample comparing to unmodified DNA. It was concluded that DNA molecules could be properly immobilized on the produced $\mathrm{CMA} / \mathrm{N}$ hybrid nanofibers via physical adsorption method and used as electrochemical DNA biosensor.
\end{abstract}

\author{
ARTICLE HISTORY \\ Received: 24.12.2018 \\ Accepted: 16.07.2019
}

\section{KEYWORDS}

Nafion, cellulose monoacetate, electrospinning, nanofibers, DNA biosensor

\section{INTRODUCTION}

Nanofibers are promising structured materials which have very broad application areas including bio-separation, filtration, wound healing, energy production and storage [1-5]. Their high surface area to volume ratio makes nanofibers preferable materials to use in the devices to enhance the device performance. For example, a high surface area of gold nanofiber electrode as fructose base biosensor was prepared by electroless deposition of gold nanoparticles on an electrospun poly(acrylonitrile)chloroauric acid tetrahydrate [6]. Electrospun poly(vinyl alcohol)/glucose oxidase composite nanofiber membranes were produced as enzymatic electrodes for biosensors by Ren et al. [7]. Titanium dioxide and zinc magnesium oxide ceramic nanofibers were prepared with enhanced optical properties via sol-gel electrospinning method [8,9].
Cellulose is a biopolymer which can be obtained or extracted from algae, plants and even bacteria [10-12]. Because of its biocompatible and environmentally friendly nature [13], it has been used in a variety of different areas including fibers for textile products [14], in vivo biomedical applications [15], etc. It is inexpensive and readly availablity including its environmetally and biocompatible properties makes cellulose a promising candidate to use in biosensor applicaitons. Cellulose and cellulose derivatives are produced in micro and nanostructured fibers forms for different applications $[16,17]$. Electrospun cellulose acetate nanofiber by loading vitamins as transdermal and dermal therapeutic agents of vitamin A acid and vitamin $\mathrm{E}$ were prepared and studied by Taepaiboon et al. [18]. Ultrafine cellulose nanofiber membranes were produced via electrospinning of cellulose acetate and the following deacetylation process [16]. Electrospinning of cellulose

To cite this article: Bostanci A., Aladag Tanik N, Aykut Y. 2019. Cellulose Monoacetate/Nafion (CMA/N) hybrid nanofibers as interface for electrochemical DNA biosensors. Tekstil ve Konfeksiyon 29(3), 228-236. 
derivatives including cellulose acetate, hydroxypropyl cellulose, hydroxypropyl methyl cellulose, and ethyl cyanoethyl cellulose was reviewed by Frey [19].

Nafion nanofibers have been fabricated via electrospinning technology by blending with other polymers. Nafion/ polyacrylonitrile blend nanofibers as the precursor of porous carbon nanofibers were prepared by Tran and Kalra [20]. Nafion/poly(ethylene oxide) composite nanofibers with an excellent shape memory properties were prepared via solution electrospinning method [21]. In another study, Dong et al. reported the preparation of Nafion/poly (ethylene oxide) nanofibers (with high Nafion contents) with high proton conductivity that is higher than the bulk Nafion film. They reported that proton conductivity increases by decreasing nanofiber diameter [22]. Polyvinyl alcohol nanofiber reinforced Nafion membranes with good mechanical and thermal properties were produced for fuel cell applications [23]. Nafion/polyvinyl alcohol composite nanofiber structures with high mechanical properties were produced by electrospinning as a functional adsorbent for heavy metals [24].

Electrochemical DNA biosensors have been used as the devices to monitor DNA damage and repair $[25,26]$ and base oxidation on a DNA molecules [27]. So, there are different applications of DNA biosensors such as clinical diagnosis [28], genetically modified organisms detection in foods [29], forensic analysis, environmental monitoring [30], etc. Nafion has been used with other materials to construct DNA biosensors. DNA damage was detected via electrochemical method by using a hemin/Nafiongraphene/glassy carbon electrode hybrid system [31]. Graphene-ionic liquid-Nafion modified pyrolytic graphite electrode (PGE) was used for the direct detection of DNA damage by electrochemical impedance spectroscopy [32]. Graphene-Nafion composite film was produced and used for a sensitive impedimetric DNA biosensor for the determination of the human immunodeficiency virus gene [33]. A DNA-based biosensor was prepared with Nafion and chitosan membrane to investigate antioxidant properties of beverages (beer, coffee, and black tea) by observing DNA degradation under in vitro conditions [34].

In this study, the preparation of Cellulose monoacetate/ Nafion $(\mathrm{CMA} / \mathrm{N})$ and their use as electrochemical DNA biosensor have been investigated. Use of the Nafion based nanofibers for electrochemical DNA biosensor applications haven't been reported yet in the literature. In this regards, the polymer blend of CMA and Nafion with the different ratio up to considering a maximum content of Nafion in hybrid nanofibers until obtaining homogeneous solutions were prepared and electrospun into nanofiber structures. Morphologies of as-spun $\mathrm{CMA} / \mathrm{N}$ hybrid nanofibers were observed by SEM, and chemical analyses of nanofibers were conducted with FTIR spectroscopy. Thermal characterizations of $\mathrm{CMA} / \mathrm{N}$ hybrid nanofibers were carried out with DSC and TGA methods. In the literature it was pointed out that Guanine in a DNA molecule oxidizes more than other bases in an appropriate condition [27]. So, electrochemical sensing properties of nanofibers were investigated by focusing on the guanine oxidation signal in adsorbed DNA molecules on $\mathrm{CMA} / \mathrm{N}$ hybrid nanofiber surfaces."

\section{MATERIAL AND METHOD}

\subsection{Chemicals for CMA/N Electrospinning Solutions}

Cellulose monoacetate powder (Mn 30.000, CMA, Sigma Aldrich) and $\sim 5 w t . \%$ of Nafion in a mixture of lower aliphatic alcohols and water solution were used for electrospinning. Electrospun polymer solutions were prepared in acetone (99\% purity) and all chemicals were used as received without further purifications.

\subsection{Electrospinning of Cellulose Monoacetate/Nafion (CMA/N) Hybrid Nanofibers}

15 wt. \% CMA was appropriately dissolved in acetone. Then, previously received Nafion solution was added into the CMA/acetone solution with the CMA/Nafion volume (solutions) ratio are $4 / 0,4 / 1,4 / 2$, and 4/3. Mix solutions were magnetically stirred until obtaining a proper homogeneous solution. The prepared solutions were electrospun into the nanofibrous structure by applying 20 $\mathrm{kV}$ voltage to the solution. $\mathrm{CMA} / \mathrm{N}$ solutions were fed with a micropump system via a plastic syringe which has a metal needled set in front of the nanofiber collector system with a distance of $\sim 10 \mathrm{~cm}$ Flow rate was $1 \mathrm{ml} / \mathrm{hr}$. Schematic illustration of the electrospinning process is shown in Figure 1. Because of the applied voltage, the solution droplet just left the needle was ejected from needle to collector. Solvents were evaporated till reaching to the collector and the mixed polymers were collected as the nanofiber forms on the collector. In order to collect nanofibers on the cylindrical graphite electrode, the PGE was attached in front of a rotating apparatus and hold between the tip of the needle and the collector. Consequently, the rotating PGEs were directly coated by these electrospun nanofibers simultaneously during the electrospinning process.

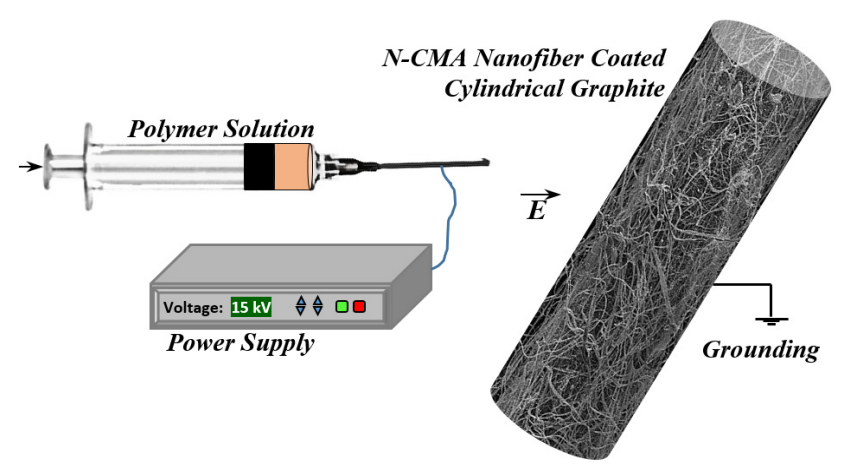

Figure 1. Schematic illustration of CMA/N hybrid nanofibers coating on the cylindrical graphite electrode.

\subsection{Characterization of Nanofibers}

The morphological characterizations of CMA/N nanofibers both on cylindrical graphite and plain surface were carried 
out with a scanning electron microscopy, SEM (ZEISS EVO 40). 15-20 kV acceleration voltages were applied during the measurements. Before SEM analysis, samples were coated with gold-palladium with around $100^{\circ} \mathrm{A}$ thickness. Chemical analyses of as-spun $\mathrm{CMA} / \mathrm{N}$ hybrid nanofibers were performed with an attenuated total reflection Fourier transform infrared spectra (ATR-FTIR, Thermo Nicolet IS50). ATR-FTIR measurements were conducted between the wavenumber ranges of 4000 to 400 $\mathrm{cm}^{-1}$. Thermal analyses of nanofibers were carried out via differential scanning calorimetry (DSC) and Thermogravimetric analysis (TGA) measurements. DSC measurements were conducted from 25 to $250^{\circ} \mathrm{C}$ with a heating rate of $10^{\circ} \mathrm{C} / \mathrm{min}$ under the nitrogen atmosphere in a measurement pan and TGA measurements were conducted from 50 to $800^{\circ} \mathrm{C}$ (heating rate of $10^{\circ} \mathrm{C} \mathrm{min}^{-1}$ ) in a nitrogen gas atmosphere.

\subsection{Probe Immobilization and Electrochemical Analysis}

Two different as unmodified and NH-modified single strand DNA probes were immobilized on CMA/N hybrid nanofibers coated cylindrical graphite electrodes, and electrochemical measurements were conducted via investigating the voltammograms of the guanine oxidation signals of probe immobilized surfaces (Figure 2). Oligonucleotide probe immobilizaiton solutions were prepared at laboratory condition in TBS $(\mathrm{pH} 7.0)$ containing $20 \mu \mathrm{M} \mathrm{NaCl}$ and $10 \mu \mathrm{g} / \mathrm{ml}$ prob. Nanofiber coated PGEs were kept $20 \mathrm{~min}$ in this solution to properly immobilized ssDNA on the nanofiber surfaces.

Nucleotide sequences of unmodified DNA's are ssDNA: 5'-GAA CAC GTG TAT GTT GAG-3' (ALPHA DNA (Canada)), and NH-modified DNA's are ssDNA: 5'-/ 5
Am/GAA CAC GTG ATA GAA GAG-3' (Sentegen (Ankara, Turkey)). Electrochemical characterizations were carried out in laboratory condition. Probe immobilization solutions of oligonucleotides of samples were prepared as in the published study [35]. Both unmodified and NHmodified ssDNA samples were immobilized on CMA/N coated pencil graphite electrodes (PGEs, (Tombo HB model $0.5 \mathrm{~mm})$ ) $[36,37]$. All the samples were washed with TBS to remove mobile ssDNA molecules. Electrochemical analyses were performed via Differential Pulse Voltammetry (DPV) measurements by using PGSTAT204 digital potentiostat/galvanostat using NOVA software package (Eco Chemie). Probe immobilized CMA/N hybrid nanofibers were used as the working electrode. The reference electrode was $\mathrm{Ag} / \mathrm{AgCl}$ and auxiliary electrodes was a platinum wire for the measurements. $1 \mathrm{~cm}$ of the probe immobilized part was immersed in ABS solution and electrochemical measurements were performed. During the electrochemical measurement, the oxidation signal of guanine was observed at about $+1,0 \mathrm{~V}$.

\section{RESULTS AND DISCUSSION}

Electrospun $\mathrm{CMA} / \mathrm{N}$ hybrid nanofibers were produced from different CMA/Nafion solutions volume ratio. Transparent homogeneous solutions were obtained up to $4 / 3$ ratio. Increasing Nafion solution ratio leads to inhomogeneous solution property and solution became blurry after 4/4 CMA/Nafion solution ratio (Figure 3A). Even blurry solutions were obtained at $4 / 4$, the solution was not electrospun into nanofiber structure at this ratio and further increasing Nafion content in the solution. Uniform hybrid $\mathrm{CMA} / \mathrm{N}$ nanofibers were collected on the cylindrical graphite electrode surfaces on a regular basis (Figure 3B and 3C).

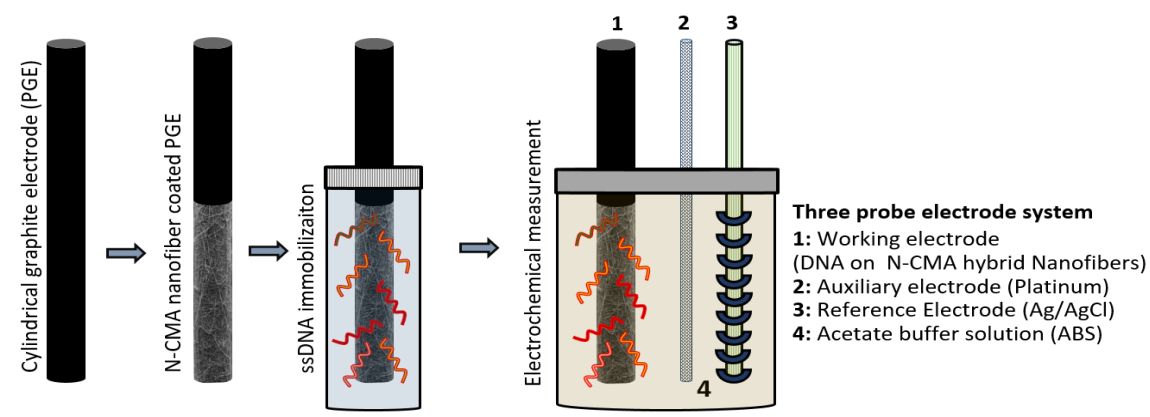

Figure 2. Schematic illustration of CMA/N nanofibers biosensor preparation and the electrochemical procedure for detecting guanine oxidation on the ssDNA.
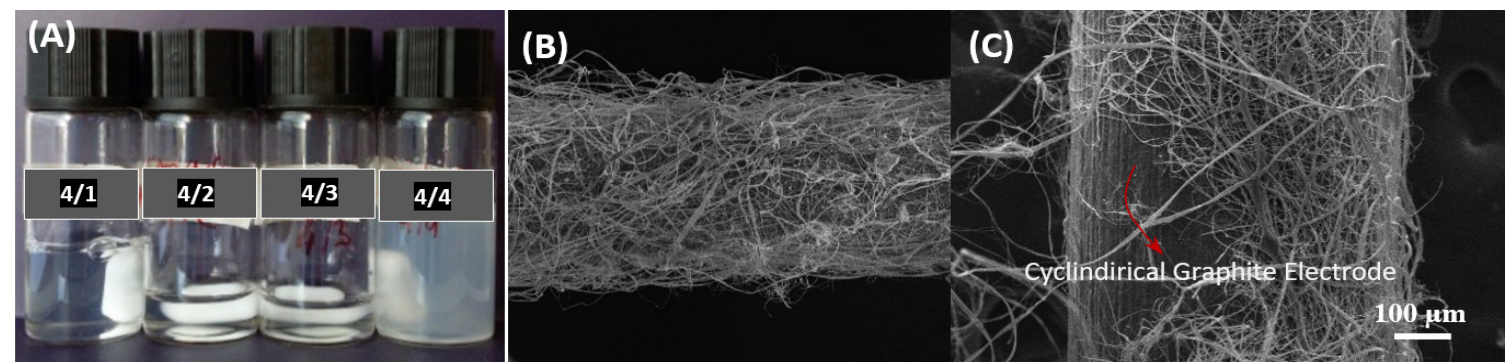

Figure 3. (A) Photograph images of prepared CMA/Nafion solutions in acetone, and (B, C) SEM images of CMA/N hybrid nanofiber coated PGEs. 


\subsection{Morphology}

Nanofibers were also collected on a plain aluminum surface to better investigate the effect of $\mathrm{CMA} /$ ratio on the nanofiber morphologies. Low magnification SEM images of pure CMA and different ratio of CMA/N hybrid nanofibers are shown in Figure 4. Pure CMA nanofibers are more uniform (Figure 4A), and increasing Nafion ratio in CMA/N hybrid nanofibers, nanofibers uniformity transforms to bead on a string morphological structures and the number of beads increases dramatically with increasing Nafion ratio in CMA/N nanofibers (Figure 4D). This might be the effect of inhomogeneous properties of the solution with increasing Nafion solution ratio.

Low and high magnification SEM images of pure CMA and $\mathrm{CMA} / \mathrm{N}$ hybrid nanofibers in $3 \mathrm{D}$ network structures are shown together in Figure 5 to better investigate the effect of polymer ratio on nanofiber uniformities. Irregularity increases tremendously with increasing Nafion ratio, nanoparticulate formations are observed on and among the nanofibers, and ultrafine nanofibers are also seen in the mat. Both ultrafine and bigger nanofibers are observed comparing pure CMA nanofibers. More flattened nanofibers structure at pure CMA, and nanofibers turned to more rounded nanofiber morphologies with the addition of Nafion.

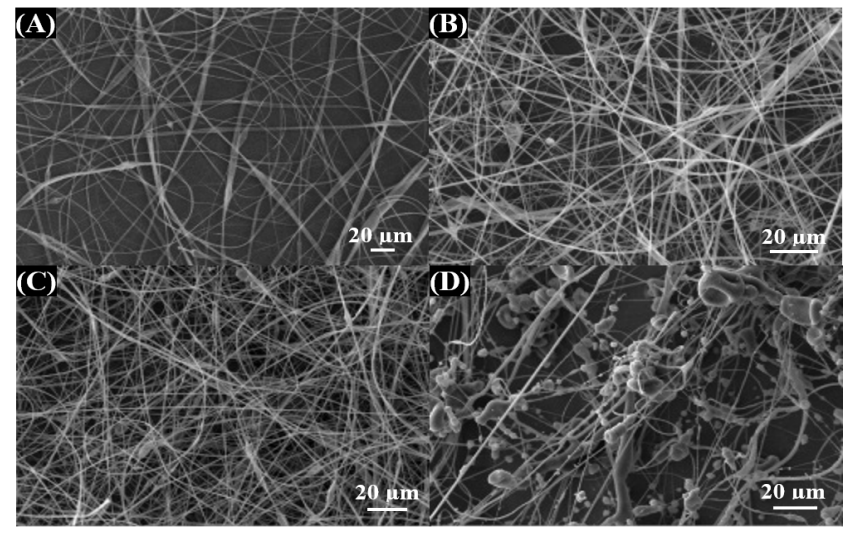

Figure 4. Low magnification SEM images of CMA/Nafion nanofibers depending on $\mathrm{CMA} / \mathrm{N}$ ratio in electrospinning solution: (A) 4/0, (B) $4 / 1$, (C) $4 / 2$, and (D) $4 / 3$


Figure 5. SEM images of CMA/Nafion nanofibers depending on CMA/N ratio in electrospinning solution: (A1, A2) 4/0, (B1, B2) 4/1, $(\mathrm{C} 1, \mathrm{C} 2) 4 / 2$, and (D1, D2) $4 / 3$. 
Electrospun fiber diameter distribution charts were given in Figure 5. Majority of fiber diameters are set between 500 $\mathrm{nm}$ and $1,5 \mu \mathrm{m}$ in pure CMA nanofibers. Addition of Nafion into CMA nanofibers causes nonhomogeneous fiber diameter distribution and two different fiber diameter phases and both nano- and micro- fibers are exist in the fibrous mat structure. Increasing the Nafion content in CMA/N hybrid nanofibers the average diameters of both nano- and micro- fibers increased in the nanofibrous mat structure.

As seen from Table 1, viscosity decreased with nafion addition into CMA/acetone solution. But, increasing nafion ration in the solution leaded to increase of viscosity again. This related to inhomogenious solution property of the solution. As seen from Figure 3, solutions were transparent at low nafion content and transformed into blurry look with increasing nafion ration. In Figure 5D, existence of thick fibers in the nanofiber mat could be related with this viscosity increase. Occurance of beaded structure in the mat could be related to increase of solution viscosity with the addition and increase of nafion content. Formations of the beaded morphologies in the nanofibrous mat structure could also be related to increase of electrical conductivity of the solution by increasing Nafion ratio. Since there is no dramatic change at the surface tension, it was concidered that there is no significant effect of surface tension on the nanofiber diameter change in this study.

\subsection{Chemical Analysis via ATR-FTIR}

ATR-FTIR investigation of pure CMA dried Nafion, and CMA/N hybrid nanofibers were demonstrated in Figure 6. In the pure CMA nanofibers, predominant peaks are located at 1047 and $1234 \mathrm{~cm}^{-1}$ related to (C-O-C), peak at $1379 \mathrm{~cm}^{-}$ ${ }^{1}$ corresponds to $\left(\mathrm{C}-\mathrm{CH}_{3}\right)$, and the peak at $1743 \mathrm{~cm}^{-1}$ can be attributed to $(\mathrm{C}=\mathrm{O}$ from acetyl groups $)[38,39] . \mathrm{OH}$ stretching band was observed as a broad peak around 3450 $\mathrm{cm}^{-1}$ [40], and this peak intensity increases and shifted to lower wavenumber by increasing Nafion ratio in CMA/N hybrid nanofibers. Since the amount of $\mathrm{HSO}_{3}$ group increase with increasing Nafion ratio, and $\mathrm{HSO}_{3}$ groups hold water molecules, $\mathrm{OH}$ stretching also increased with increasing Nafion ratio as a result of absorbed water molecules [41]. Characteristic Nafion peaks were seen at CMA/N hybrid nanofibers. Peaks at 1141 and $1205 \mathrm{~cm}^{-1}$ correspond to the symmetric and asymmetric stretching vibrations modes of $-\mathrm{CF}_{2}[21,42]$. Bending vibration of $\mathrm{CF}_{2}$ was detected at $632 \mathrm{~cm}^{-1}$ [21]. The peak at $1057 \mathrm{~cm}^{-1}$ is related to the $\mathrm{SO}_{3} \mathrm{H}$ groups and it can be attributed to the stretching vibration of $\mathrm{SO}_{3}[21,43]$. The peaks are seen at 966 and $986 \mathrm{~cm}^{-1}$ may arise from the stretching vibration of C-O-C, respectively [42, 43]. Characteristic peaks come from Nafion were not seen clearly at CMA/N hybrid nanofibers that may be due to mostly CMA molecules exist at the surface of the nanofibers.

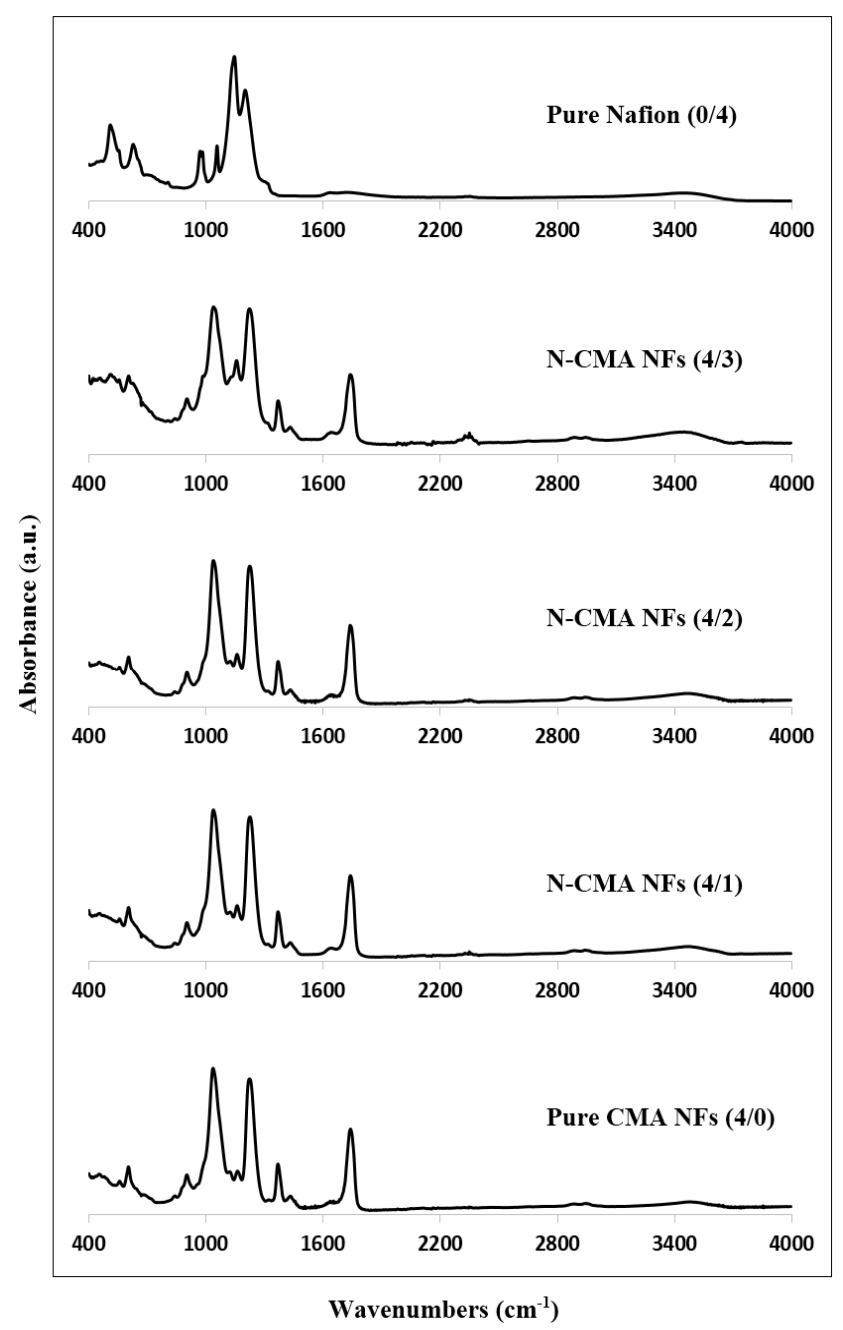

Figure 6. ATR-FTIR spectra of CMA/Nafion hybrid nanofibers with differing mixing ratio.

Table 1. Characteristics of measured electrospinning solution parameters

\begin{tabular}{|c|c|c|c|c|}
\hline CMA/N Ratio & Shear viscosity $(\mathrm{cP})$ & Surface tension $\left(\mathrm{mN} \mathrm{m}^{-1}\right)$ & Conductivity & $\left(\mu \mathrm{S} \mathrm{cm}^{-1}\right)$ \\
\hline $4 / 0$ & 700 & 31.52 & & 6 \\
\hline $4 / 1$ & 500 & 33.05 & & 65 \\
\hline $4 / 2$ & 400 & 34.98 & & 127 \\
\hline $4 / 3$ & 600 & 34.30 & & 237 \\
\hline
\end{tabular}

${ }^{\mathrm{a}} \mathrm{CMA} / \mathrm{N}=$ Cellulose monoacetate/Nafion hybrid nanofiber 


\subsection{Thermal Analysis of As-spun NFs with DSC and TGA}

Pure CMA nanofibers (Figure 7a) present a broad peaks around $226{ }^{\circ} \mathrm{C}$, which is associated with the melting temperature of CMA nanofibers [2]. Glass transition of CMA is detected around $197{ }^{\circ} \mathrm{C}$ [44]. Even though melting temperature is clearly seen at CMA nanofibers, since it may be Nafion addition does not allow an appropriate crystallization of CMA, melting points for CMA are not detectable at $\mathrm{CMA} / \mathrm{N}$ hybrid nanofibers. These peaks disappeared with the addition of Nafion to CMA as a result of a proper blend of Nafion and CMA in the electrospinning solution (This can be seen at the transparent solution phase in Figure 3A). The broad peaks observed around 150,157 and $161^{\circ} \mathrm{C}$ for $4 / 3,4 / 2$ and $4 / 1 \mathrm{CMA} / \mathrm{N}$ hybrid nanofiber samples may be associated to thermal energy absorbed to loosen the strong association of the pendant sulfonic acid groups [45]. This peak shifts to higher temperature with increasing CMA content in CMA/N hybrid nanofibers (Figure 7d).

Thermal stability and weight loss with the temperature of pure CMA and CMA/N hybrid nanofibers in a nitrogen atmosphere are observed by TGA and DTG plots and demonstrated in Figure 8. Weight loss between $50-100^{\circ} \mathrm{C}$ corresponds to the removal of water from the nanofibers. As it is seen from the TGA plot, comparing pure CMA nanofibers weight loss originated from water removal is higher at $\mathrm{CMA} / \mathrm{N}$ nanofibers and increase with increasing Nafion ratio since more water molecules are held by CMA/N hybrid nanofibers. Single major weight loss is observed around between $272-398^{\circ} \mathrm{C}$ for pure CMA nanofibers that related to removal of volatiles produced from the decomposition of the polymer [46]. Major weight loss is divided into different parts and weight loss temperature fluctuated at $\mathrm{CMA} / \mathrm{N}$ hybrid nanofibers. Thermal degradation temperature decreases dramatically with the addition of Nafion into CMA nanofibers and decomposition occurs at a broad temperature range. Residual of the materials after TGA measurements are about $18.05,20.02$ and 20.01 wt. $\%$ respectively for $4 / 0,4 / 1$ and $4 / 3 \mathrm{CMA} / \mathrm{N}$ hybrid nanofibers.

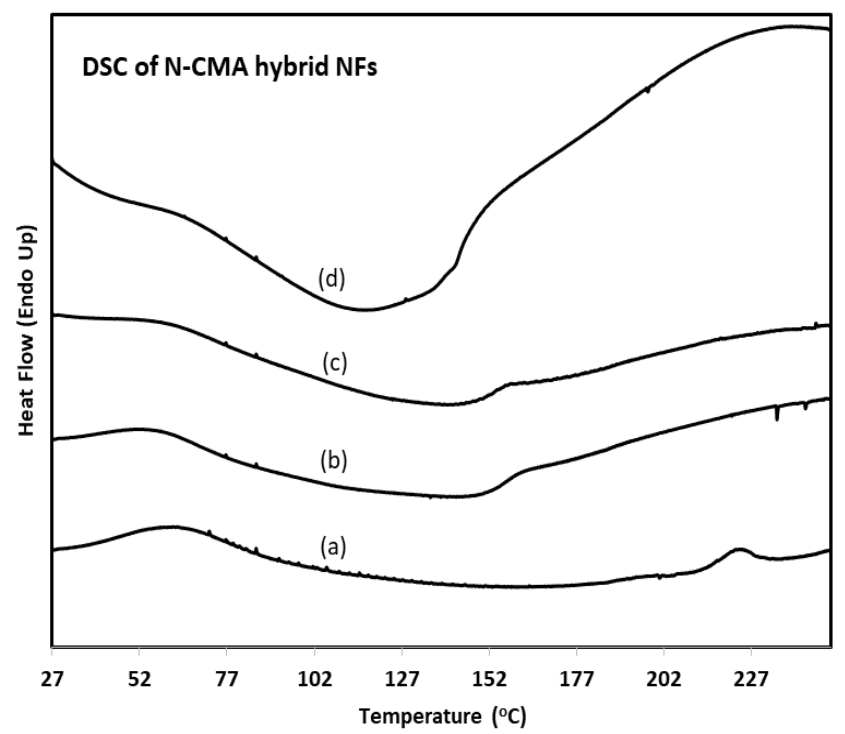

Figure 7. DSC thermograms of $\mathrm{CMA} / \mathrm{N}$ hybrid nanofibers depending on $\mathrm{CMA} / \mathrm{N}$ ratio in electrospinning solution: (a) $4 / 0$, (b) $4 / 1$, (c) $4 / 2$, and (d) $4 / 3$.
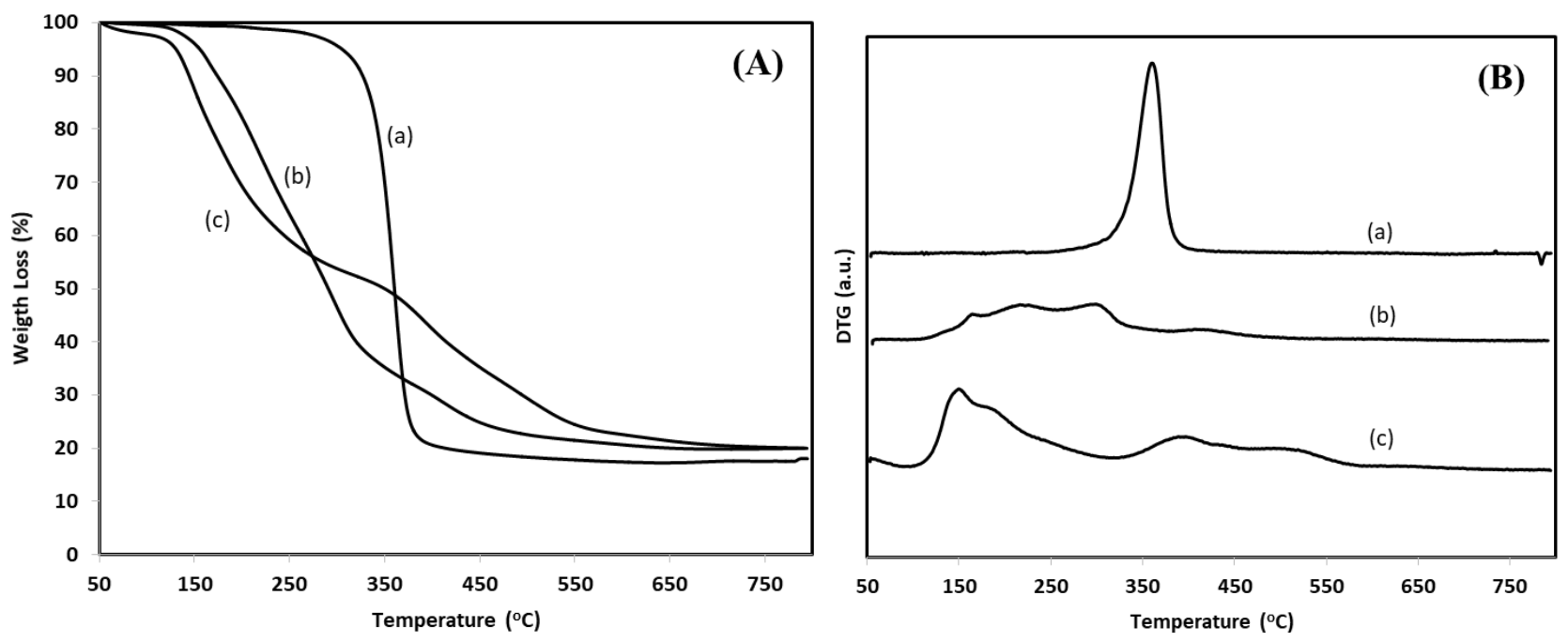

Figure 8. (A) TGA and (B) DTG thermograms of CMA/N hybrid nanofibers in nitrogen gas atmosphere (depending on CMA/Nafion ratio in electrospinning solution): (a) 4/0, (b) $4 / 1$, (c) $4 / 3$. 


\section{a. Electrochemical Biosensor Analysis of As-spun Hybrid NFs}

As mentioned that electrochemically guanine oxidation is most detectable than other bases, so guanine oxidation signal is focused in this study [47]. During the electrochemical measurement, oxidation signal of guanine was observed at about $+1,0 \mathrm{~V}$ by using CMA/N nanofiber electrodes for both neat ssDNA (Figure 9A) and $\mathrm{NH}$ modified (Figure 9B) ssDNA samples. As it is seen from Figure 9A, signal intensity is maximum $(1.69 \mu \mathrm{A})$ for pure CMA nanofibers at neat ssDNA sample. Intensities are $1.69,1.16,0.89,1.27 \mu \mathrm{A}$ for $4 / 0,4 / 1,4 / 2$ and $4 / 3$ for neat ssDNA on CMA/N nanofiber samples tested sequentially. Initial addition of Nafion into CMA nanofibers decreased the signal intensity comparing to pure CMA nanofibers. Increasing the Nafion ratio in $\mathrm{CMA} / \mathrm{N}$ nanofibers first decreased the intensity of the signal and increased it again if the Nafion ratio continuously increased, but the signal intensity did not pass the intensity of pure CMA. Intensities are $0.09,0.38,1.06,0.79 \mu \mathrm{A}$ for $4 / 0,4 / 1,4 / 2$ and $4 / 3$ for $\mathrm{NH}$-modified ssDNA on CMA/N nanofiber samples tested sequentially. Comparing neat DNA, signal intensity increases with the addition of Nafion into CMA/N nanofibers at NH-modified ssDNA sample since it may be an interaction between $\mathrm{NH}$ groups on ssDNA and $\mathrm{SO}_{3}$ groups on Nafion. Negatively charged Nafion molecules in $\mathrm{CMA} / \mathrm{N}$ hybrid nanofibers could be interacted more positively charged guanine bases between biosensor surface and ssDNA molecule leads to signal enhancement [48]. Hu et al. reported that DNA molecules could be bonded to sulfonic groups from the amine groups of DNA [49]. So, NH modified DNA molecules could be strongly attached to the nafion containing CMA nanofibers comparing to unmodified DNA samples and the electrochemical signal intensity could be enhanced. Guanine oxidation enhancement was also reported by Cam et al, by addition of polyaniline into polyacrylonitrile nanofibers [35]. DNA molecules were physically adsorbed on the polyacrylonitrile/polyaniline nanofibers and the signal enhancement was related to the conductive nature of polyaniline comparing. So, it was concluded that if there is a strong interaction between the surface of nanofibers and the DNA molecules, the electrochemical signal intensity increases properly.

\section{CONCLUSION}

In this study, cellulose monoacetate/Nafion hybrid nanofibers have been fabricated via electrospinning technique on the cylindrical graphite substrates. Increasing the Nafion ratio leads to inhomogeneous solution property and solution transform from transparent to blurry phase. At the same time, nanofibers morphologies transform from uniform structure to bead on a string defect morphology with increasing Nafion ratio in $\mathrm{CMA} / \mathrm{N}$ hybrid nanofibers. Neat and NH-modified single strand DNA molecules were immobilized on as-prepared nanofiber-PGE systems. Guanine oxidation signal intensity changes were observed regarding CMA and addition of Nafion into CMA/N nanofibers at $\mathrm{NH}$-modified ssDNA. The strong interaction between biosensor surface and ssDNA molecule leads to signal enhancement. The examined CMA/N hybrid nanofibers could be a promising interface for DNA biosensor devices.

\section{ACKNOWLEDGEMENT}

This study was supported by Scientific Research Project Unit (BAP) of Bursa Uludağ University, under project number: KUAP (MH) 2018/11. The authors thank Bursa Uludag University. The study is Ayşe Bostancı's Master thesis at the Graduate School of Natural and Applied Sciences, Bursa Uludağ University. Ayse Bostancı thanks to Karima Sahtani for her help on nanofiber preparation.
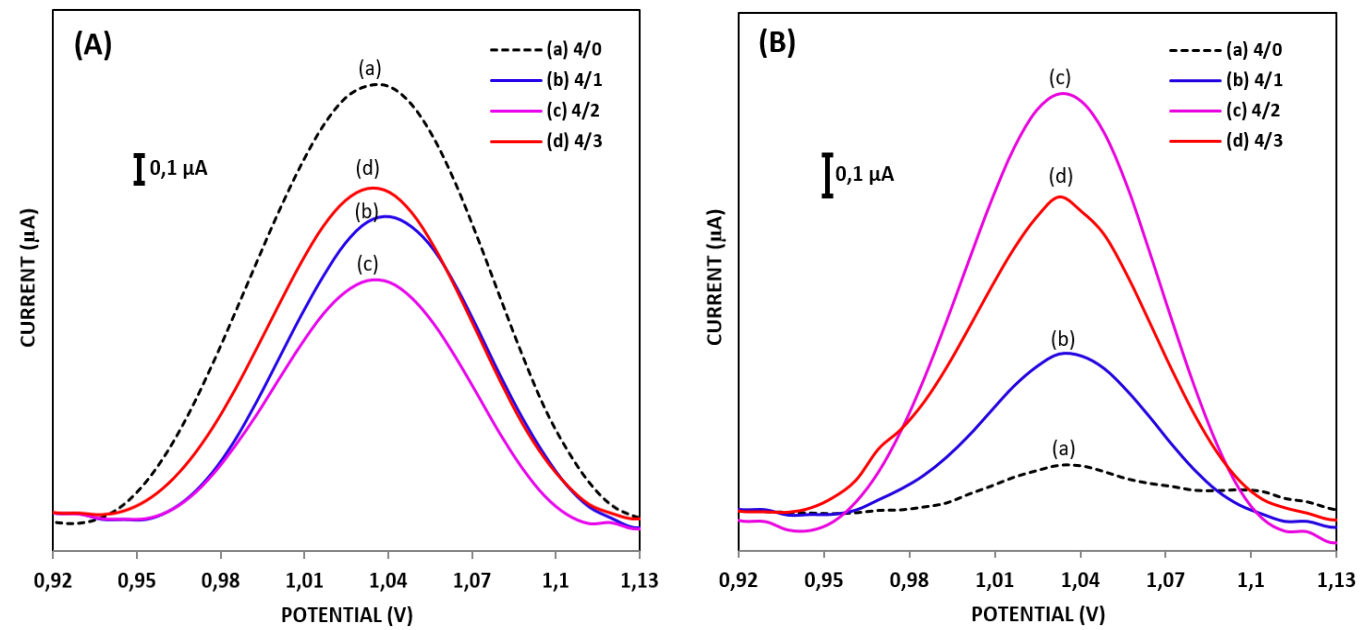

Figure 9. Electrochemical measurements: Voltammograms of the guanine oxidation signals of probe coated surfaces. (A) ssDNA, (B) NH-modified ssDNA 


\section{REFERENCES}

1. Zhang L, Menkhaus TJ, Fong H. 2008. Fabrication and bioseparation studies of adsorptive membranes/felts made from electrospun cellulose acetate nanofibers, Journal of Membrane Science 319, 176184.

2. Ma Z, Kotaki M, Ramakrishna S. 2005. Electrospun cellulose nanofiber as affinity membrane, Journal of Membrane Science 265 $115-123$.

3. Croisier F, Jerome C. 2013. Chitosan-based biomaterials for tissue engineering, European Polymer Journal 49, 780-792.

4. Kim ID, Hong JM, Lee BH, Kim DY, Jeon EK, Choi DK, Yang DJ. 2007. Dye-sensitized solar cells using network structure of electrospun ZnO nanofiber mats, Applied Physics Letter 91, 163109.

5. Bai Y, Wang Z, Wu C, Xu R, Wu F, Liu Y, Li H, Li Y, Lu J, Amine K. 2015. Hard carbon originated from polyvinyl chloride nanofibers as high-performance anode material for Na-ion battery, ACS Applied Materials Interfaces 7(9), 5598-5604.

6. Marx S, Jose MV, Andersen JD, Russell AJ. 2011. Electrospun gold nanofiber electrodes for biosensors, Biosensensors and Bioelectronics 26, 2981-2986.

7. Ren G, Xu X, Liu Q, Cheng J, Yuan X, Wu L, Wan Y. 2006 Electrospun poly(vinyl alcohol)/glucose oxidase biocomposite membranes for biosensor applications, Reactive Functional Polymers 66, 1559-1564.

8. Aykut Y, Saquing CD, Pourdeyhimi B, Parsons GN, Khan S.A 2012. Templating quantum dot to phase-transformed electrospun $\mathrm{TiO}_{2}$ nanofibers for enhanced photo-excited electron injection, ACS Applied Materials Interfaces 4(8), 3837-3845.

9. Aykut Y, Parsons GN, Pourdeyhimi B, Khan SA. 2013. Synthesis of mixed ceramic MgxZn1-xO nanofibers via Mg2+ doping using SolGel electrospinning Langmuir. 29 (12), 4159-4166.

10. Liu Y, Chen JY. 2016. Enzyme immobilization on cellulose matrixes, Journal of Bioactive and Compatible Polymers 31, 553 567.

11. Esa F, Tasirin SM, Rahman NA. 2014. Overview of Bacterial Cellulose Production and Application, Agriculture and Agricultural Science Procedia 2, 113-119.

12. Ek R, Gustafsson C, Nutt A, Iversen T, Nyström C. 1998. Cellulose powder from Cladophora sp. algae, Journal of Molecular Recognition 11, 263-265.

13. Credou J, Berthelot T. 2014. Cellulose: From biocompatible to bioactive material, Journal of Materials Chemistry B 2, 4767-4788.

14. Majumdar A, Mukhopadhyay S, Yadav R. 2010. Thermal properties of knitted fabrics made from cotton and regenerated bamboo cellulosic fibres, International Journal of Thermal Sciences 49, 20422048 .

15. Helenius G, Bäckdahl H, Bodin A, Nannmark U, Gatenholm P, Risberg B. 2006. In vivo biocompatibility of bacterial cellulose, Journal of Biomedical Materials Research 76A, 431-438.

16. Liu H, Hsieh YL. 2002. Ultrafine fibrous cellulose membranes from electrospinning of cellulose acetate, Journal of Polymer Science Part B Polymer Physics 40, 2119-2129.

17. Fan X, Zhang T, Zhao Z, Ren H, Zhang Q, Yan Y, Lv G. 2013 Preparation and characterization of bacterial cellulose microfiber/goa bone apatite composites for bone repair, Journal of Applied Polymer Science 129, 595-603.

18. Taepaiboon P, Rungsardthong U, Supaphol P. 2007. Vitamin-loaded electrospun cellulose acetate nanofiber mats as transdermal and dermal therapeutic agents of vitamin A acid and vitamin E, European Journal of Pharmaceutics Biopharmaceutics 67, 387-397.

19. Frey M.W. 2008. Electrospinning cellulose and cellulose derivatives, Polymer Reviews 48, 378-391.
20. Tran C, Kalra V. 2013. Co-continuous nanoscale assembly of Nafion-polyacrylonitrile blends within nanofibers: A facile route to fabrication of porous nanofibers, Soft Matter 9, 846-852.

21. Zhang F, Zhang Z, Liu Y, Leng J. 2014. Shape memory properties of electrospun nafion nanofibers, Fibers and Polymers 15, 534-539.

22. Dong B, Gwee L, Salas-De La Cruz D, Winey KI, Elabd YA. 2010. Super proton conductive high-purity nafion nanofibers, Nano Letters 10(9), 3785-3790.

23. Molla S, Compan V. 2011. Polyvinyl alcohol nanofiber reinforced Nafion membranes for fuel cell applications, Journal of Membrane Science 372, 191-200.

24. Sharma DK, Li F, Wu YN. 2014. Electrospinning of Nafion and polyvinyl alcohol into nanofiber membranes: A facile approach to fabricate functional adsorbent for heavy metals, Colloids Surfaces A Physicochemical Engineering Aspects 457, 236-243.

25. Fojta M, Daňhel A, Havran L, Vyskočil V. 2016. Recent progress in electrochemical sensors and assays for DNA damage and repair, TrAC - Trends in Analytical Chemistry 79, 160-167.

26. Palecek E, Fojta M, Tomschik M, Wang J. 1998. Electrochemical biosensors for DNA hybridization and DNA damage, Biosensors and Bioelectronics 13, 621-628.

27. Halliwell B. 2000. Why and how should we measure oxidative DNA damage in nutritional studies? How far have we come?, The American Journal of Clinical Nutrition 72, 1082-1087.

28. Lee HE, Kang YO, Choi SH. 2014. Electrochemical-DNA biosensor development based on a modified carbon electrode with gold nanoparticles for influenza a (H1N1) detection: Effect of spacer, International Journal of Electrochemical Science 9, 6793- 6808.

29. Jamaluddin RZAR, Heng LY, Tan LL, Chong KF. 2018. A Biosensor for Genetic Modified Soybean DNA Determination via Adsorption of Anthraquinone-2-sulphonic Acid in Reduced Graphene Oxide, Electroanalysis 30, 250-258.

30. Wang J, Rivas G, Cai X, Palecek E, Nielsen P, Shiraishi H, Dontha N, Luo D, Parrado C, Chicharro M, Farias P.A.M, Valera FS, Grant DH, Ozsoz M, Flair MN. 1997. DNA electrochemical biosensors for environmental monitoring, Analytica Chimica Acta 347, 1-8.

31. Ni Y, Wang P, Song H, Lin X, Kokot S, 2014. Electrochemical detection of benzo(a)pyrene and related DNA damage using DNA/hemin/nafion-graphene biosensor, Analytica Chimica Acta 821, 34-40.

32. Qiu Y, Qu X, Dong J, Ai S, Han R. 2011. Electrochemical detection of DNA damage induced by acrylamide and its metabolite at the graphene-ionic liquid-Nafion modified pyrolytic graphite electrode, Journal of Hazardous Materials 190, 480-485.

33. Gong Q, Wang Y, Yang H. 2017. A sensitive impedimetric DNA biosensor for the determination of the HIV gene based on grapheneNafion composite film, Biosensors and Bioelectronics 89, 565-569.

34. Hlavatá L, Vyskočil V, Beníková K, Borbélyová M, Labuda J. 2014 DNA-based biosensors with external Nafion and chitosan membranes for the evaluation of the antioxidant activity of beer, coffee, and tea, Central European Journal of Chemistry 12(5), 604611.

35. Cam E, Aladag Tanik N, Cerkez I, Demirkan E, Aykut Y. 2018 Guanine oxidation signal enhancement in single strand DNA with polyacrylonitrile/polyaniline (PAN/PAni) hybrid nanofibers, Journal of Applied Polymer Science 135(3), 45567.

36. Aladag N, Trnkova L, Kourilova A, Ozsoz M, Jelen F. 2010 Voltammetric Study of Aminopurines on Pencil Graphite Electrode in the Presence of Copper Ions, Electroanalysis 22, 1675-1681.

37. Topkaya SN, Aydinlik S, Aladag N, Ozsoz M, Ozkan-Ariksoysal D. 2010. Different DNA immobilization strategies for the interaction of anticancer drug irinotecan with DNA based on electrochemical DNA biosensors, Combinatorial Chemistry \& High Throughput Screening $13,582-589$. 
38. Joshi MK, Tiwari AP, Pant HR, Shrestha BK, Kim HJ, Park CH, Kim CS. 2015. In Situ Generation of Cellulose Nanocrystals in Polycaprolactone Nanofibers: Effects on Crystallinity, Mechanical Strength, Biocompatibility, and Biomimetic Mineralization, ACS Applied Materials \& Interfaces 7 (35), 19672-19683.

39. Zhao Y, Zhu X, Liu H, Luo Y, Wang S, Shen M, Zhu M, Shi X. 2014 Dendrimer-functionalized electrospun cellulose acetate nanofibers for targeted cancer cell capture applications, Journal of Materials Chemistry B 2, 7384-7393.

40. Liu R, Peng Y, Cao J, Chen Y. 2014. Comparison on properties of lignocellulosic flour/polymer composites by using wood, cellulose, and lignin flours as fillers, Composite Science Technology 103, 1-7.

41. Jiang G, Zhang J, Qiao J, Jiang Y, Zarrin H, Chen Z, Hong F. 2015. Bacterial nanocellulose/Nafion composite membranes for low temperature polymer electrolyte fuel cells, Journal of Power Sources $273,697-706$

42. Yao Y, Li J, Lu H, Gou J, Hui D. 2015. Investigation into hybrid configuration in electrospun nafion/silica nanofiber, Composites Part B Engineering 69, 478-483.

43. Shao ZG, Wang X, Hsing IM. 2002. Composite Nafion/polyvinyl alcohol membranes for the direct methanol fuel cell, Journal of Membrane Science 210, 147-153.
44. Ali S, Khatri Z, Oh KW, Kim IS, Kim SH. 2014. Zein/cellulose acetate hybrid nanofibers: Electrospinning and characterization, Macromolecular Research 22, 971-977.

45. Guo B, Liu Z, Hong L. 2011. Doping Nafion ${ }^{\circledR}$ matrix by p-aramid flakes for a proton transport less reliant on moisture, Journal of Materials Chemistry 21, 12414-12421.

46. Li R, Dou J, Jiang Q, Li J, Xie Z, Liang J, Ren X. 2014. Preparation and antimicrobial activity of $\beta$-cyclodextrin derivative copolymers/cellulose acetate nanofibers, Chemical Engineering Journal $248,264-272$.

47. Halliwell B. 2000. Why and how should we measure oxidative DNA damage in nutritional studies? How far have we come?,The American Journal of Clinical Nutrition 72, 1082-1087.

48. Yin $\mathrm{H}$, Zhou Y, Ma Q, Ai S, Ju P, Zhu L, Lu L. 2010. Electrochemical oxidation behavior of guanine and adenine on graphene-Nafion composite film modified glassy carbon electrode and the simultaneous determination, Process Biochemistry 45, 17071712 .

49. Hu YW, Yang T, Wang XX, Jiao K. 2010. Highly Sensitive Indicator-Free Impedance Sensing of DNA Hybridization Based on Poly(m-aminobenzenesulfonic acid)/ $/ \mathrm{TiO}_{2}$ Nanosheet Membranes with Pulse Potentiostatic Method Preparation, Chemistry - A European Journal 16, 1992-1999. 